\section{Estudo \\ cobebate}

em Cestão

Planejamento
Revista Estudo \& Debate, Lajeado, v. 27, n. 3, 2020. ISSN 1983-036X

DOI: http://dx.doi.org/10.22410/issn.1983-036X.v27i3a2020.2528

\title{
ANÁLISE DO CONSUMO DE COMBUSTÍVEIS DO SETOR DE TRANSPORTE RODOVIÁRIO NO BRASIL
}

\author{
Arney Rayol Moura de Araújo ${ }^{1}$, Elane Conceição de Oliveira ${ }^{2}$
}

\begin{abstract}
Resumo: A situação climática mundial continua se deteriorando, e em 2018, o IPCC (Intergovernmental Panel on Climate Change) lançou um novo relatório em que enfatiza que o impacto humano na natureza é inevitável, mas pode ser reduzido se os países adotarem metas mais ambiciosas de reduçâo do efeito estufa. Diante disso, essa pesquisa buscou estudar o consumo dos combustíveis ligados ao setor de transporte rodoviário no Brasil e suas respectivas emissóes de $\mathrm{CO}_{2}$, de 2005 a 2016, visto que este é o segundo setor que mais emite $\mathrm{CO}_{2}$ no Brasil, observando na análise sua relação com a economia, e acontecimentos que impactaram em seus mercados consumidores. Esta pesquisa identificou que as emissóes de $\mathrm{CO}_{2}$ de 2009 em diante cresceram acima do nível de crescimento da economia, o que indica perda de eficiência no consumo destes combustíveis no Brasil.
\end{abstract}

Palavras-chave: automóveis, efeito-estufa, dióxido de carbono, eficiência energética.

\section{ANALYSIS OF FUEL CONSUMPTION IN THE ROAD TRANSPORT SECTOR IN BRAZIL}

\begin{abstract}
The global climate situation continues to deteriorate, and in 2018, the IPCC released a new report which emphasizes that the human impact on nature is inevitable, but can be reduced if countries adopt more ambitious targets for reducing greenhouse effect. Therefore, this research sought to study the consumption of fuels linked to the road transport sector in Brazil and their respective $\mathrm{CO}_{2}$ emissions, from 2005 to 2016, since this is the second sector that emits more $\mathrm{CO}_{2}$ in Brazil, observing in the analysis its relationship with the economy, and events that impacted their consumer markets. This research identified that $\mathrm{CO}_{2}$ emissions from 2009 onwards grew above the level of economic growth, which indicates loss of efficiency in the consumption of these fuels in Brazil.
\end{abstract}

Keywords: automobiles, greenhouse effect, carbon dioxide, energy efficiency.

1 Graduando em Ciências Econômicas na Universidade do Estado do Amazonas - UEA.

2 Economista, professora adjunta na Universidade do Estado do Amazonas - UEA. 


\section{INTRODUÇÁO}

Em 2018, o IPCC destacou a importância de limitar o aumento da temperatura terrestre em $1,5^{\circ}$ em relação aos níveis pré-industriais até o ano de 2100 . O relatório destaca que os seguintes problemas serão enfrentados devido à elevação da temperatura média da terra: má temperatura na maior parte da terra e regiōes oceânicas, temperaturas extremas na maioria das regióes habitadas, chuvas pesadas em várias regiōes, probabilidade de seca e baixos níveis de chuvas em algumas regióes, aumento dos níveis dos mares, impactos nos ecossistemas e na biodiversidade, aumento na temperatura média nos oceanos e também em seu nível de acidez e queda no nível de oxigenação, riscos à saúde, segurança alimentícia, suprimento de água, crescimento econômico, e segurança à humanidade (IPCC, 2018). Se essa meta for alcançada o mundo enfrentará menores desafios no futuro, reduzindo o tamanho destes problemas, visto que não podem ser evitados.

Os Gases de Efeito Estufa (GEE) são constituintes gasosos da atmosfera, naturais e antropogênicos, os quais absorvem e emitem radiação em comprimentos de onda específicos dentro do espectro de radiação terrestre emitida pela superfície da Terra, a própria atmosfera e pelas nuvens (IPCC, 2014). Embora não possam absorver a radiação vinda do sol, podem reter a radiaçáo de retorno (MENDONÇA; GUTIEREZ, 2000). Esta propriedade causa o efeito estufa.

$\mathrm{O} \mathrm{CO}_{2}$ é o principal GEE que afeta o balanço radioativo da terra. É um gás que existe naturalmente na natureza, mas também é um subproduto da queima de combustíveis fósseis, queima de biomassas, processos industriais, e mudanças no uso da terra (IPCC, 2014). Isso se deve ao fato de estar associado à produção e consumo de energia em termos globais, e a sua permanência na atmosfera ser bastante duradoura (MENDONÇA; GUTIEREZ, 2000).

Em termos mundiais, o setor industrial é o maior emissor de $\mathrm{CO}_{2}(32 \%)$; seguido pela Agricultura, Floresta e outros usos da terra (25\%); pela Construção (18\%); e os Transportes apresentam-se como quarto colocado (14\%); Outros (11\%) (IPCC, 2014). De acordo com o Observatório do Clima (2019), no ano de 2016, o Brasil emitiu 1.649.380.072 $\mathrm{tCO}_{2}$, atribuídos 51,83\% à Mudança do Uso da Terra, 24,03\% à Energia, 19,42\% à Agropecuária, 4,07\% aos Processos Industriais, e 0,01\% aos Resíduos.

O protagonismo da Mudança do Uso da Terra como maior emissor de $\mathrm{CO}_{2}$ se deve a elevada participação de energia renovável na matriz energética brasileira, e ao fato do consumo de combustíveis no Brasil ainda ser modesto em comparaçấo com outras economias industrializadas. Segundo Olivier, Schure e Peters (2018), aumentar a participação de fontes de energia renovável na oferta interna de energia total é uma tendência na reduçấo das emissóes de $\mathrm{CO}_{2}$ observada pelo mundo. Tolmasquim, Guerreiro e Gorini (2007) alerta que possuir uma matriz energética com uma participação mais alta de fontes de energia renovável não significa que o país possa minimizar a importância do crescimento das emissóes nacionais, devendo adotar medidas que garantam que o desenvolvimento não traga elevação considerável das emissóes de $\mathrm{CO}_{2}$.

Nesse contexto, esta pesquisa ganha importância, pois o consumo de combustíveis associados ao setor de transporte rodoviário torna-se um importante instrumento para 
guiar a tomada de políticas públicas que incentivem o consumo de biocombustíveis ante os combustíveis fosseis, e investimentos no transporte coletivo.

O objetivo da pesquisa é calcular, para o período de 2005 a 2016, as emissóes de $\mathrm{CO}_{2}$ pelo consumo de gasolina $\mathrm{C}$ e óleo diesel no Brasil. Será realizada uma análise sobre o consumo destes combustíveis e do etanol hidratado, bem como das emissóes de $\mathrm{CO}_{2}$. Também irá calcular a intensidade energética do produto, fazendo uma análise desta ao longo do período analisado.

\section{REVISÃO DA LITERATURA}

A qualidade de vida e competitividade econômica dos países sofre forte influência da disponibilidade de energia desde a revolução industrial. As economias que melhor se posicionam quanto ao acesso aos recursos energéticos de menor custo e impacto ambiental obtêm importante vantagem comparativa. Em um ambiente de maior crescimento econômico também é maior o crescimento da demanda de energia. Nesse contexto, é importante promover o consumo mais eficiente da energia (TOLMASQUIM; GUERREIRO; GORINI, 2007).

Em 2012, as diversas atividades consumidoras de combustíveis fósseis foram responsáveis por 90,6\% das emissóes de $\mathrm{CO}_{2}$ no mundo (JANSSENS-MAENHOUT et al., 2019). De acordo com Olivier, Schure e Peters (2017), substituir o consumo de combustíveis fósseis mais poluidores por outros combustíveis fósseis menos poluidores, e aumentar a participação de fontes de energia renovável na oferta interna de energia total, são algumas tendências na redução das emissóes de $\mathrm{CO}_{2}$ observadas pelo mundo.

O Brasil possui emissóes de GEE relativamente baixas, em razão da participação de fontes de energia renováveis na oferta interna de energia. Isso não significa que o país possa minimizar a importância do crescimento das emissóes nacionais, devendo adotar medidas que garantam que o desenvolvimento não traga elevação considerável das emissões de GEE (TOLMASQUIM; GUERREIRO; GORINI, 2007).

Segundo estudos do Laboratório de Poluição Atmosférica Experimental, da Faculdade de Medicina da Universidade de São Paulo (USP), mais de 200 doenças estão associadas à poluição do ar, levando inclusive a morte de cerca de 3 mil pessoas por ano apenas na região metropolitana de São Paulo (SALDIVA et al., 2007, apud CARVALHO, 2011).

Segundo os dados do IPCC (2006), dos combustíveis usados no setor de transporte rodoviário, o óleo diesel é o combustível que mais emite carbono, e consequentemente $\mathrm{CO}_{2}$, com fator de emissão de 20,2 tC/TJ, a gasolina possui fator de emissão de 18,9 tC/TJ. Para o Ministério da Ciência e Tecnologia (MCT), o etanol hidratado possui fator 14,81 tC/TJ, apesar disso, é um biocombustível com baixo impacto ao meio ambiente, devido ao sequestro de carbono ocorrido durante o plantio da cana. Para o IPCC (2006), o $\mathrm{CO}_{2}$ emitido por fontes renováveis não deve ser contabilizado nos inventários de emissóes.

A gasolina e o óleo diesel são subprodutos do petróleo, e, portanto, combustíveis fósseis. Para contornar a elevada emissão $\mathrm{CO}_{2}$ por combustíveis fósseis existem no Brasil políticas que determinam a mistura de biocombustíveis a esses combustíveis, como forma 
de mitigar as emissóes de $\mathrm{CO}_{2}$ não renovável. $\mathrm{O}$ etanol anidro é misturado à gasolina, e o biodiesel ao diesel (KOHLHEPP, 2010).

Os veículos a diesel correspondem por pequena parcela dos deslocamentos diários urbanos, mas são responsáveis por grande parte das emissóes de GEE (CARVALHO, 2011).

A idade média da frota brasileira de caminhóes em 2009 era de aproximadamente 19 anos, o que é bastante elevado, e quanto mais velho os veículos mais GEE emitem por não terem as tecnologias mais recentes que geram maior eficiência no consumo de combustíveis e lubrificantes, e ainda perdem eficiência no consumo de combustíveis com a idade, consumindo mais combustíveis e consequentemente emitindo mais GEE (CRUVINEL; PINTO; GRANEMANN, 2012).

De acordo com D冈rner e Braun (2015), grande parte dos financiamentos feitos pelo BNDES (Banco Nacional de Desenvolvimento Econômico e Social) destinados à modernização da indústria brasileira é, na verdade, aplicado do lado da demanda como estímulo a aquisição de novos veículos, especialmente caminhóes. Tal fato tem como consequência o aumento da frota de veículos consumidores de diesel no Brasil.

Segundo o relatório de gestão do exercício de 2016 do BNDES, o Fundo Garantidor de Investimentos (FGI), criado em 2009 e administrado pelo BNDES, possui três programas para o financiamento à compra de caminhóes. São eles: o Procaminhoneiro Novo, o Procaminhoneiro Usado, e o Ônibus/Caminhão. Entre 2009 e 2016, o Procaminhoneiro Novo financiou R \$ 2,9 bilhóes em aquisição de caminhóes ou 50,5\% do total financiado pelo fundo, o Ônibus/Caminhão financiou $\mathrm{R} \$ 767$ milhóes em aquisição de caminhóes e ônibus, ou 13,28\% do total financiado pelo fundo, e o Procaminhoneiro Usado financiou $\mathrm{R}$ \$ 386 milhões em aquisição de caminhóes, ou 6,69\% do total financiado pelo fundo. Os valores nesse relatório comprovam a grande concentração das açôes do BNDES do lado da demanda.

O etanol é um biocombustível que se destaca como importante instrumento para a redução das emissóes de $\mathrm{CO}_{2}$. O etanol pode ser produzido da cana-de-açúcar, da beterraba, ou do amido vindo de diversas fontes como o milho. O Brasil produz o etanol da cana-deaçúcar. Desde 2003 passou-se a produzir em massa carros equipados com motores flex-fuel, os quais permitem que os veículos trafeguem usando gasolina, etanol, ou qualquer mistura entre os dois, trazendo um grande impulso a demanda por etanol (KOHLHEPP, 2010).

Entretanto, a crise deflagrada na segunda metade de 2008 trouxe desconfiança aos investidores que financiavam o mercado sucroenergético. Devido ao aumento do endividamento do setor, o que já tornava mais difícil a aquisição de novos débitos, a crise trouxe ainda mais dificuldade de aquisição de novos débitos para gerar investimentos no setor, o endividamento do setor havia ocorrido pela expectativa de o Brasil se tornar um grande exportador de etanol, o que não se concretizou (MORAES; BACCHI, 2015).

Problemas de investimento, devido à falta de recursos financeiros no período, fatores climáticos negativos e desconhecimento de práticas adequadas de uso dos fatores de mecanização da colheita, impactaram na produção de etanol nas safras 2010-2011 e 2011 2012 (MORAES; BACCHI, 2015). 
Desde 2006 era mais rentável produzir açúcar ao invés de etanol, o que fazia com que se priorizasse a produção do primeiro em relação ao segundo. A política de manutenção dos preços da gasolina tornava o etanol menos competitivo o que tornava os lucros da venda de etanol menores, e levava a uma maior priorização da produção de açúcar (MORAES; BACCHI, 2015).

\section{METODOLOGIA}

A pesquisa faz uso de métodos de estimação das emissóes de $\mathrm{CO}_{2}$ do IPCC, o qual é apresentado na primeira sessão, e um indicador da intensidade energética do produto adaptada para as emissóes de $\mathrm{CO}_{2}$ e VAB, apresentado na segunda sessão. Utiliza dados secundários disponíveis no site da ANP, e, no Balanço Energético Nacional (BEN) publicado pela Empresa de Pesquisa Energética (EPE).

\subsection{Emissóes de $\mathrm{CO}_{2}$}

O IPCC fornece dois modelos para o cálculo das emissóes de $\mathrm{CO}_{2}$, os quais são especificados a seguir:

O primeiro modelo é a abordagem de referência ou Top-Down, onde se estima as emissôes de $\mathrm{CO}_{2}$ diretamente pelo consumo aparente dos combustíveis, sem se especificar de que forma esses combustíveis foram consumidos, a partir do uso dos fatores de emissão defalt disponibilizados pelo próprio IPCC (MATTOS, 2001).

O segundo modelo é a abordagem setorial ou Botton-Up, onde se estima as emissóes de $\mathrm{CO}_{2}$ para cada subgrupo de veículos com características similares, desde que existam dados locais detalhados e confiáveis sobre a tecnologia de motorização utilizada, qualidade do combustível, consumo, quilometragem, fatores de emissão levantados em laboratórios locais, estado de manutenção da frota, etc (ÁLVARES; LINKE, 2001).

Os dados sobre o consumo de combustíveis no Brasil foram fornecidos pela Agência Nacional Do Petróleo, Gás Natural e Biocombustíveis (ANP), e são provenientes das vendas e do consumo próprio de combustíveis pelas distribuidoras de combustíveis. Esta pesquisa toma os dados do consumo de etanol hidratado, gasolina c e óleo diesel de 2005 a 2016.

A presente pesquisa adota o modelo Top-Down, já bastante utilizado por diversos autores nacionais, a exemplo: Mattos (2001); Cruvinel, Pinto e Granemann (2012); Álvares e Linke (2001); Gomes, Faria e Dallemole (2010). No modelo se multiplica o consumo aparente de combustíveis $(\mathrm{CA})$, aqui dispostos como $\mathrm{M}^{3}$, pelo fator de conversão $\left(\mathrm{F}_{\text {conv }}\right)$ para a unidade de referência, o tep, a partir do qual se pode transformar na unidade energética adotada pelo IPCC, o J, considerando a quantidade de calorias contidas em um tep e sua equivalência em TJ, obtendo-se assim o consumo de energia (CC) (MATTOS, 2001).

Os dados sobre o fator de conversão em tep são definidos no Balanço Energético Nacional (BEN), o qual também define quantas calorias tem um tep. Vale ressaltar que desde 2003 o BEN passou a adotar os critérios internacionais mais usuais para a conversão de unidades comerciais de energia em uma unidade comum de referência, então o petróleo de referência passou a ser o de $10000 \mathrm{kcal} / \mathrm{kg}$, e todos os fatores de conversão passaram 
a ser determinados com base nos poderes caloríficos inferiores das fontes de energia. Por isso o tep brasileiro passou a ter $10000 \mathrm{Mcal}$, equivalente a $41,868^{*} 10^{\wedge}-3 \mathrm{TJ}$. Os fatores de conversão são: 0,770 para a gasolina c; 0,848 para o óleo diesel; e 0,510 para o etanol hidratado.

O IPCC determina que se use o poder calorifico inferior para conversão em J, pois os fatores de emissão são baseados na energia efetivamente aproveitável do combustível. Trabalhos anteriores possuíam um fator de correção $\left(\mathrm{F}_{\text {corr }}\right)$ nesse ponto para que o valor calculado estivesse de acordo com os métodos do IPCC. Portanto a primeira fórmula:

$$
\mathrm{CC}=\mathrm{CA}^{*} \mathrm{~F}_{\text {conv }} * 41,868^{*} 10^{\wedge}-3
$$

Com o consumo de energia (CC) se pode calcular a quantidade de carbono (QC) emitida na queima do combustível usando os fatores de emissão $\left(\mathrm{F}_{\text {emiss }}\right)$ que o IPCC define para cada combustível, considerando a emissáo de tC para o consumo de 1TJ, e depois multiplicando por $10^{\wedge}-3$ para que o resultado seja disposto em $\mathrm{GgC}$, como manda o IPCC. É importante destacar que o IPCC incentiva os pesquisadores a utilizarem dados de fatores de emissão que melhor definam a realidade de uma região, estado ou país, ao invés dos valores defalt que podem não ser representativos para todas as regióes do mundo. Os fatores de emissão são:18,9 para a gasolina c; 20,2 para o óleo diesel; e 14,81 para o etanol hidratado. Assim a segunda fórmula:

$$
\mathrm{QC}=\mathrm{CC}^{*} \mathrm{~F}_{\text {emiss }}^{*} 10^{\wedge}-3
$$

Alguns combustíveis são empregados para fins não energéticos, como a produção de plásticos, asfalto, lubrificante entre outros. Assim parte do carbono fica estocada ou fixada (QCF). Para biomassas sólidas e líquidas 100\% do carbono é estocado, pois o carbono emitido na queima do combustível foi previamente sequestrado na produção da biomassa, ou o município que planta a cana-de-açúcar registra o sequestro de carbono e o município que a queima registra a emissão. Nesta pesquisa o etanol é o único combustível que tem seu carbono fixado, no caso $100 \%$. Dessa forma, e também para enfatizar que este biocombustível tem baixo impacto ao processo de superaquecimento do planeta, não se calculará as emissóes dele.

A partir da quantidade de carbono emitida pode-se calcular as emissóes de $\mathrm{CO}_{2}$ $\left(\mathrm{ECO}_{2}\right)$, usando para isso a relação entre os pesos moleculares do dióxido de carbono e do carbono, sendo que em $44 \mathrm{tCO}_{2}$ corresponde a 12 tC (ÁLVARES; LINKE, 2001), entretanto deve-se considerar que nem todo o carbono existente no combustível será oxidado. Para os combustíveis analisados considera-se que 1\% do carbono será incorporado as cinzas ou outros subprodutos (MATTOS, 2001). Apresenta- se a terceira fórmula:

$$
\mathrm{ECO}_{2}=\mathrm{QC}^{*} 44 / 12 * 0,99
$$




\subsection{Intensidade Energética do Produto}

Mendonça e Gutierez (2000) conceituam que o grau de intensidade energética do produto (IEP) é medido pela razão entre o consumo total de energia e o produto da economia. É um indicador da tendência do crescimento no padrão de emissão de $\mathrm{CO}_{2}$, e argumentam que o aumento da eficiência energética seria a manutençáo do mesmo tipo e nível de renda a partir de uma quantidade menor de energia. Tem-se a fórmula indicada:

$$
\mathrm{IEP}=\frac{\text { Consumo Total de Energia }}{\text { PIB }}
$$

Para os fins dessa pesquisa usou-se uma fórmula da intensidade energética do produto (IEP) adaptada, passando a indicar a relação entre as emissóes de $\mathrm{CO}_{2}$ e o Valor Adicionado Bruto da economia. Esse indicador faz uma análise tão superficial da eficiência do consumo, e consequentemente emissóes, quanto o anterior.

Esse indicador remove o peso dos impostos do cálculo, considerando que o tamanho dos impostos na economia influencia os níveis de produção, consumo, e renda, ou seja, se houvesse uma redução da carga tributária, e consequente queda no PIB, haveria um crescimento da produção, consumo, e renda, e consequente aumento no PIB, sendo difícil dizer quanto seria este aumento em relação à queda na participação dos impostos no PIB (DORNBUSCH; FISCHER; STARTZ, 2013). E para os fins desta pesquisa busca-se saber apenas o valor dos bens e serviços efetivamente consumidos pela economia. Assim, tem-se a fórmula:

$$
\mathrm{IEP}=\frac{\text { Emissões de } \mathrm{CO} 2}{\text { Valor Adicionado Bruto }}
$$

O Valor Adicionado Bruto (VAB) para o período analisado foi fornecido pelo IBGE. Para evitar distorçóes no resultado provenientes da inflação, o VAB de 2005 foi tomado como ano base e os dos anos seguintes foram encontrados considerando apenas a variação no volume da economia. O VAB foi disposto em milhóes de reais para fins de simplificação.

\section{RESULTADOS E DISCUSSŌES}

Os dados serão apresentados em quatro seções: a primeira discutirá o consumo dos combustíveis no Brasil, cujos dados foram retirados da ANP, a segunda será acerca das emissóes de $\mathrm{CO}_{2}$ dos combustíveis analisados no Brasil, estimados a partir do abordagem de referência do IPCC, a terceira será sobre o VAB do Brasil, e, por fim, a quarta será sobre a intensidade energética do produto do Brasil.

\subsection{Consumo de Combustíveis no Brasil}

O diesel é um combustível importante para os veículos pesados, rodoviários e urbanos, e sua análise ganha importância em tempos recentes devido à demonstrada capacidade que os caminhoneiros possuem de influenciar a economia. 
De acordo com o Gráfico 1, de 2005 a 2008, o consumo de óleo diesel cresceu a uma taxa média de 4,55\% ao ano, passando de $39167,1 \mathrm{mil} \mathrm{M}^{3}$, em 2005, para 44763,9 mil $\mathrm{M}^{3}$, em 2008, tais taxas seguem o nível de crescimento da economia brasileira. Cai aproximadamente $1 \%$ em 2009, e volta a crescer a uma taxa média de $6,27 \%$ de 2009 a 2014, taxa maior que o nível de crescimento da economia brasileira. Cai 4,7\% e 5,1\%, em 2015 e 2016, respectivamente, devido à crise econômica, sendo uma queda maior que a queda da economia brasileira.

O consumo de óleo diesel de 2009 a 2014 cresceu mais que o crescimento da economia brasileira devido ao grande crescimento da frota de veículos consumidores de diesel, principalmente caminhôes, adquiridos através de financiamentos do BNDES. O óleo diesel é o combustível fóssil que mais emite $\mathrm{CO}_{2}$ analisado nesta pesquisa, por isso não é desejado que o consumo deste crescesse artificialmente, ao fazer isso o Brasil foi no sentido oposto de tendências internacionais de redução das emissóes de $\mathrm{CO}_{2}$.

De acordo com o Gráfico 1, de 2005 a 2009, o consumo de gasolina c cresceu a uma taxa média de 1,91\% ao ano, passando de 23553,5 mil M 3 , em 2005, para 25409,1 $\mathrm{mil} \mathrm{M}^{3}$, em 2009, uma taxa de crescimento modesta devido ao crescimento da oferta de etanol, o qual é substituto da gasolina. Passa a crescer a uma taxa média de 11,79\% ao ano de 2009 a 2014, impulsionado pela crise no setor sucroenergético e pela política de manutenção de preços da gasolina. Cai a uma taxa média 1,53\% ao ano de 2014 a 2016.

Gráfico 1 - Consumo de gasolina c, óleo diesel e etanol hidratado no Brasil, de 2005 a 2016.

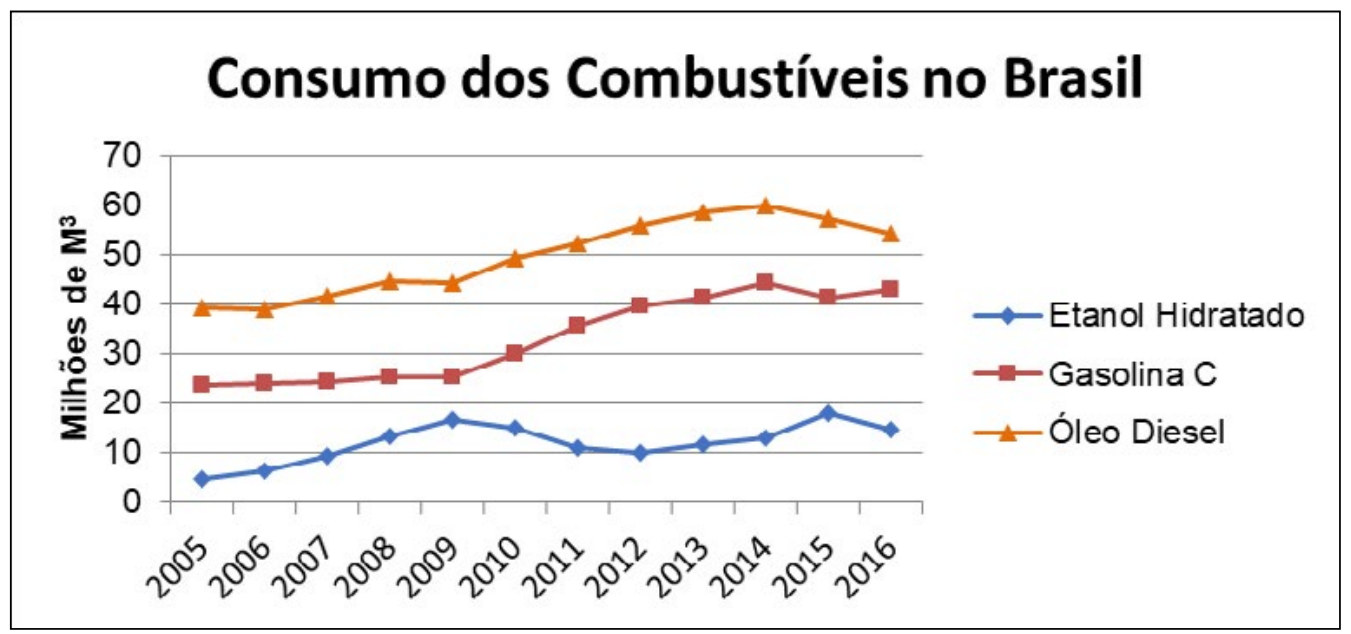

Fonte: Elaboração própria a partir dos dados da ANP.

De acordo com o Gráfico 1, de 2005 a 2009, o consumo de etanol hidratado cresceu a uma taxa média de $37,06 \%$ ao ano, passando de $4667,2 \mathrm{mil} \mathrm{M}^{3}$, em 2005, para 16470,9 mil $\mathrm{M}^{3}$, em 2009, devido à tecnologia dos motores fex-fuel, que tornaram o etanol um substituto direto da gasolina, o que gerou um grande mercado consumidor em potencial para o etanol, e a expectativa de o Brasil se tornar um grande exportador de etanol. Passou a 
cair a uma taxa média de $15,75 \%$ ao ano de 2009 a 2012, e volta a crescer a uma taxa média de $10,31 \%$ ao ano de 2012 a 2016.

A crise no setor sucroenergético, devido a dificuldades de aquisição de débitos para reinvestimento no setor, e a política de manutenção de preços da gasolina nos anos seguintes, a qual foi uma política que aumentou a crise e retardou a recuperaçáo deste setor, gerou uma grande queda na oferta de etanol após 2009. Os consumidores passaram entâo a consumir gasolina em maiores quantidades nos anos seguintes. A política de manutenção de preços da gasolina foi, por isso, no sentido oposto às tendências internacionais de reduçáo das emissóes de $\mathrm{CO}_{2}$, por incentivar o consumo de um combustível fóssil em detrimento de um renovável.

O ano de 2015 chama a atenção para o consumo de gasolina e etanol, os quais são combustíveis substitutos, a gasolina cai $3226,8 \mathrm{mil} \mathrm{M}^{3}$ e o etanol cresce $4868,6 \mathrm{mil} \mathrm{M}^{3}$. Sabendo-se que se X litros de gasolina andam $1 \mathrm{~km}$, os mesmos X litros de etanol andam 0,7 $\mathrm{km}$, o etanol a mais consumido em 2015 equivale a $3408 \mathrm{M}^{3}$ de gasolina. Isso indica que em 2015 muitos consumidores substituíram a gasolina pelo etanol mantendo a distância percorrida relativamente à mesma. Tal fenômeno não se repetiu novamente.

\subsection{Emissóes de $\mathrm{CO}_{2}$ no Brasil}

As emissōes de $\mathrm{CO}_{2}$ estimadas nesta pesquisa são obtidas pela conversão do consumo de cada combustível em emissóes de $\mathrm{CO}_{2}$, logo as taxas de crescimento das emissóes de $\mathrm{CO}_{2}$ são iguais às taxas de crescimento do consumo de cada combustível, porém a definição de qual combustível emite mais por $\mathrm{m}^{3}$ consumido é definido pelos fatores usados na conversão de cada combustível em $\mathrm{CO}_{2}$.

Cada $\mathrm{M}^{3}$ de gasolina emite cerca de 2,2 $\mathrm{tCO}_{2}$,e cada $\mathrm{M}^{3}$ de diesel emite cerca de 2,6 $\mathrm{tCO}_{2}$, o que o torna o combustível que individualmente emite mais $\mathrm{CO}_{2}$ analisado nesta pesquisa. As emissóes de $\mathrm{CO}_{2}$ do etanol foram ignoradas por este possuir uma elevada quantidade de carbono sequestrada durante o plantio da cana, e ter um baixo impacto ao processo de superaquecimento do planeta. 
Gráfico 2 - Emissóes de $\mathrm{GgCO}_{2}$, pelos combustíveis gasolina c e óleo diesel no Brasil, de 2005 a 2016.

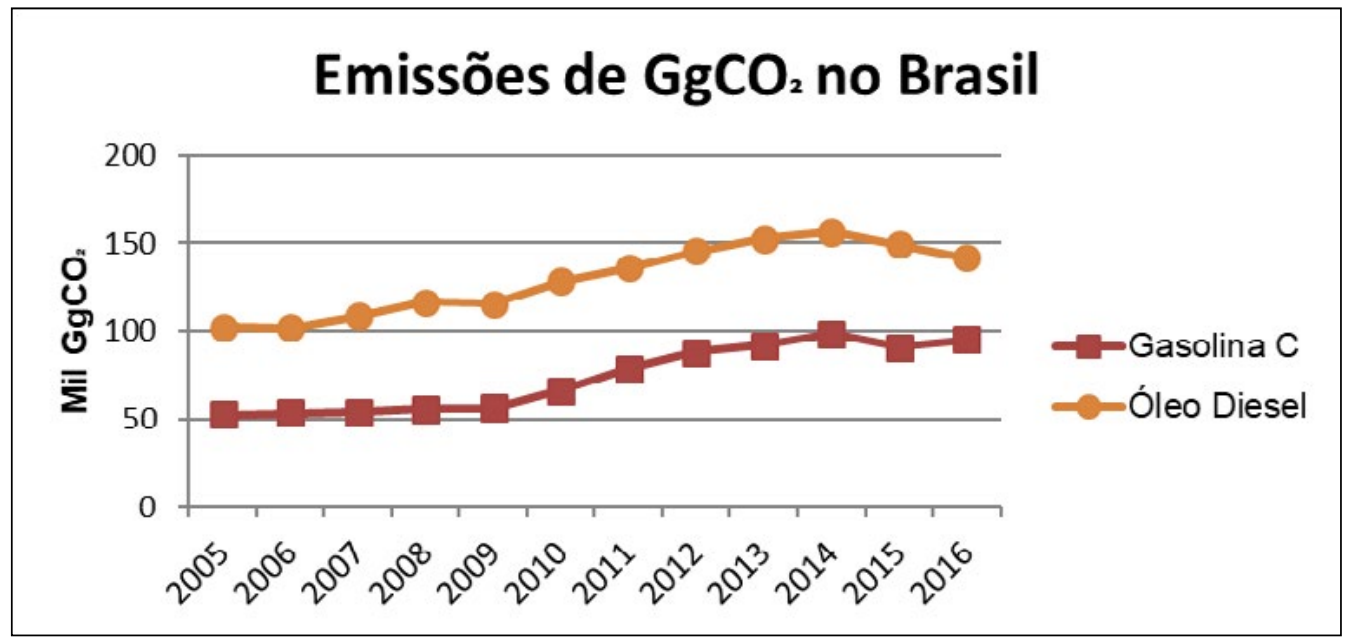

Fonte: Elaboração própria a partir dos dados da ANP.

De acordo com o Gráfico 2, de 2005 a 2008, as emissóes de $\mathrm{CO}_{2}$ do óleo diesel cresceu a uma taxa média de 4,55\% ao ano, passando de 102 mil $\mathrm{GgCO}_{2}$ em 2005 para 116,5 mil $\mathrm{GgCO}_{2}$ em 2008, caindo aproximadamente $1 \%$ em 2009. Volta a crescer a uma taxa média de 6,27\% de 2009 a 2014, passando de 115,3 mil $\mathrm{GgCO}_{2}$ em 2009 para 156,3 mil $\mathrm{GgCO}_{2}$ em 2014. Cai 4,7\% e 5,1\%, em 2015 e 2016, respectivamente, passando para 141,3 mil $\mathrm{GgCO}_{2}$ em 2016, devido à crise econômica. Observa-se pelo Gráfico 2 que este é o combustível mais poluidor aqui estudado.

De acordo com o Gráfico 2, de 2005 a 2009, as emissóes de $\mathrm{CO}_{2}$ da gasolina c cresceram a uma taxa média de 1,91\% ao ano, passando de 52,1 mil $\mathrm{GgCO}_{2}$ em 2005 para 56,2 mil $\mathrm{GgCO}_{2}$ em 2009. Passa a crescer a uma taxa média de $11,79 \%$ ao ano de 2009 a 2014, para 98,1 mil GgCO em 2014, impulsionado pela crise do setor sucroenergético e pela política de manutenção de preços da gasolina. Cai a uma taxa média 1,53\% ao ano de 2014 a 2016.

\subsection{Valor Adicionado Bruto do Brasil}

A Tabela 1 mostra o VAB de 2005 a 2016 a preços constantes de 2005, para evitar distorçôes provenientes da inflação, e disposto em milhôes de reais. Pode-se verificar na Tabela 1 que de 2005 a 2008, o VAB constante cresceu a uma taxa média de 4,72\% ao ano, caindo aproximadamente $0,01 \%$ em 2009 , devido a crise de 2009 , e volta a crescer a uma taxa média 3,11\% de 2009 a 2014, caindo 3,1\% em 2015 e 2,9\% em 2016, devido à crise econômica. 
Tabela 1 - Valor Adicionado Bruto, em milhóes de reais, de 2005 a 2016, no Brasil, a preços constantes, ano base 2005.

\begin{tabular}{cc}
\hline Brasil & R\$ $\mathbf{1 . 0 0 0 . 0 0 0 , 0 0}$ \\
\hline Ano & VAB Constante, ano base $=\mathbf{2 0 0 5}$ \\
\hline 2005 & $\mathrm{R} \$ 1.842 .818,40$ \\
\hline 2006 & $\mathrm{R} \$ 1.910 .748,66$ \\
\hline 2007 & $\mathrm{R} \$ 2.021 .556,94$ \\
\hline 2008 & $\mathrm{R} \$ 2.116 .097,21$ \\
\hline 2009 & $\mathrm{R} \$ 2.114 .047,68$ \\
\hline 2010 & $\mathrm{R} \$ 2.261 .527,59$ \\
\hline 2011 & $\mathrm{R} \$ 2.346 .179,78$ \\
\hline 2012 & $\mathrm{R} \$ 2.383 .998,42$ \\
\hline 2013 & $\mathrm{R} \$ 2.452 .556,45$ \\
\hline 2014 & $\mathrm{R} \$ 2.463 .862,83$ \\
\hline 2015 & $\mathrm{R} \$ 2.386 .249,23$ \\
\hline 2016 & $\mathrm{R} \$ 2.316 .224,79$ \\
\hline
\end{tabular}

Fonte: Elaborado pelos autores a partir dos dados do IBGE.

A partir desses dados é possível perceber que o consumo de óleo diesel cresceu acima do crescimento econômico de 2010 a 2014, e teve uma queda muito mais acentuada em 2015 e 2016, comparado à economia. Tal crescimento pode ser explicado pela disponibilização de linhas de crédito para a aquisição de caminhôes pelo governo via BNDES.

\subsection{Intensidade Energética do Produto no Brasil}

O Gráfico 3 mostra as emissões de $\mathrm{GgCO}_{2}$ para cada 1 milhão de reais de $\mathrm{VAB}$, quanto menor o valor desse indicador mais eficiente é a economia em relação as emissóes de $\mathrm{CO}_{2}$, significando a manutenção de um mesmo nível de renda a partir de uma quantidade menor $\mathrm{CO}_{2}$ emitido. 
Gráfico 3 - Intensidade energética do produto considerando as emissóes de $\mathrm{CO}_{2}$ da gasolina c e óleo diesel, pelo VAB no Brasil, de 2005 a 2016.

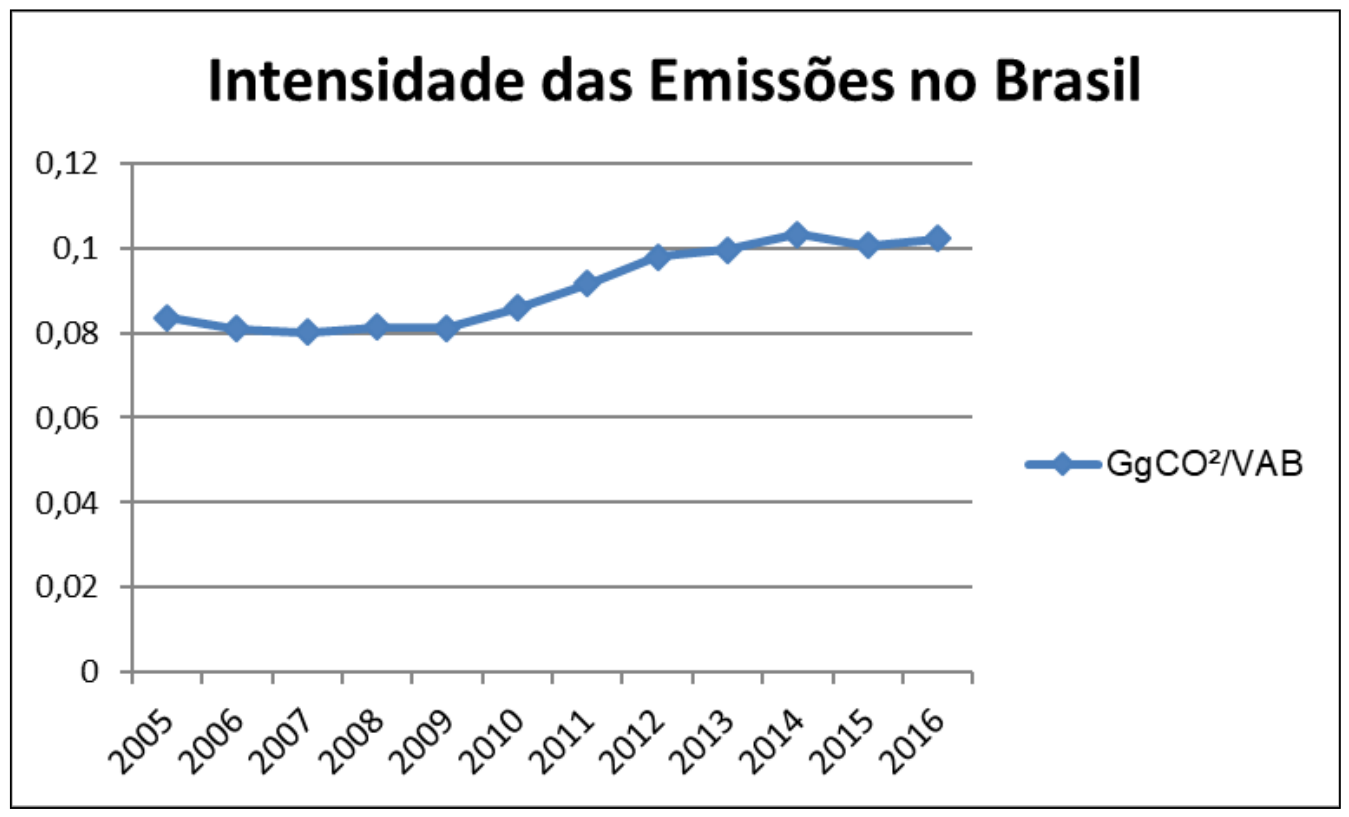

Fonte: Elaboração própria a partir dos dados da ANP e IBGE.

De acordo com o Gráfico 3, a IEP era próxima de 0,08 até o ano de 2009, após isso passa a crescer a uma taxa média de $4,94 \%$ ao ano, alcançando $0,103 \mathrm{GgCO}_{2} / 1000000 \mathrm{VAB}$ em 2014, ante $0,081 \mathrm{GgCO}_{2} / 1000000 \mathrm{VAB}$ em 2009. Em 2015 e 2016 a crise econômica reduz o consumo de combustíveis fósseis, em especial o diesel, e interrompe o crescimento desse valor.

Para fazer comparação, em 2008 a gasolina era responsável por $0,026 \mathrm{GgCO}_{2} / 1000000$ $\mathrm{VAB}$ enquanto o diesel era de $0,055 \mathrm{GgCO}_{2} / 1000000 \mathrm{VAB}$, ao passo que em 2014 a gasolina era responsável por $0,04 \mathrm{GgCO}_{2} / 1000000 \mathrm{VAB}$ e o diesel era de $0,063 \mathrm{GgCO}_{2} / 1000000$ $\mathrm{VAB}$. Isso mostra que houve perda de eficiência no consumo dos dois combustíveis, no sentido estrito desse indicador, causado pelo aumento do consumo da gasolina, devido à crise no setor sucroenergético, e pelo aumento do consumo do diesel, devido ao crescimento da frota de veículos consumidores de diesel, principalmente caminhóes, ambos acima do nível de crescimento econômico no período.

\section{CONSIDERAÇÓES FINAIS}

O desenvolvimento econômico traz consigo o aumento da demanda por combustíveis em geral, e o indicador da intensidade energética do produto do Brasil passou de 0,081 $\mathrm{GgCO}_{2} / 1000000 \mathrm{VAB}$ em 2009 para $0,103 \mathrm{GgCO}_{2} / 1000000 \mathrm{VAB}$ em 2014 . Isso mostra que está havendo um crescimento muito maior do consumo de combustíveis fosseis, especificamente a gasolina e o diesel, em relação ao crescimento da economia, trazendo perda na eficiência das emissóes de $\mathrm{CO}_{2}$ para cada 1 milhão de VAB gerado no Brasil. 
O aumento da demanda por gasolina ocorreu devido à crise do setor sucroenergético a partir de 2009, e também pela política de manutenção de preços da gasolina, que reduziu a oferta de etanol e incentivou o consumo de gasolina, fazendo o consumo deste crescer a uma taxa média de $11,79 \%$ ao ano de 2009 a 2014, ante uma taxa média de $1,91 \%$ ao ano de 2005 a 2009. A política de manutenção de preços da gasolina foi negativa do ponto de vista ambiental, indo no sentido oposto às tendências internacionais de redução das emissōes de $\mathrm{CO}_{2}$, por incentivar o consumo de um combustível fóssil em detrimento de um renovável.

O motivo do aumento da demanda por diesel foi causado, principalmente, pelo crescimento da frota de veículos consumidores de diesel, principalmente caminhôes, no Brasil, via financiamento do BNDES, pois a demanda deste deveria crescer a taxas semelhantes ao crescimento da economia, porém, enquanto o VAB do Brasil crescia a uma taxa de $3,11 \%$ ao ano de 2009 a 2014, a demanda por diesel, cresceu a uma taxa média de $6,27 \%$ ao ano de 2009 a 2014 . A queda da demanda por diesel do setor maior que a queda da produçáo econômica em 2015 e 2016, pode indicar a criaçáo de fragilidade para o setor por esta política. Mas o verdadeiro problema para esta pesquisa é que se emite mais $\mathrm{CO}_{2}$ na atmosfera desnecessariamente, sendo uma política com um impacto ambiental negativo.

Em suma, o Brasil passou a emitir mais $\mathrm{CO}_{2}$ devido à crise no setor sucroenergético, deflagrada pela crise de 2008, a política de manutençáo de preços da gasolina, e a grande oferta de financiamentos para a compra de veículos consumidores de diesel, principalmente caminhōes, pelo BNDES. O governo conseguiu afetar negativamente, do ponto de vista ambiental, o consumo de etanol hidratado, gasolina c e óleo diesel através dessas duas medidas tomadas.

Esta pesquisa, no entanto, náo é conclusiva, e o assunto do setor de transporte rodoviário pode ser aprofundado por pesquisas posteriores que agreguem mais dados de novas fontes, e novos métodos.

\section{REFERÊNCIAS}

ÁLVARES JR, Olimpio de Melo.; LINKE, Renato Ricardo Antonio. Metodologia simplificada de cálculo das emissóes de gases do efeito estufa de frotas de veículos no Brasil. CETESB, v. 182, 2001.

\section{BRASIL, ANP. Vendas, pelas Distribuidoras, dos Derivados Combustíveis de}

Petróleo. Disponível em: < http://www.anp.gov.br/arquivos/dados-estatisticos/vendascombustiveis/vendas-combustiveis-m3.xls >. Acesso em: 29 junho 2020.

BNDES. RELATÓRIO DE GESTÃO DO EXERCÍCIO DE 2016. 2017.

Disponível em: < https:/www.bndes.gov.br/wps/wcm/connect/site/ef1e0277-3b61-4dee86e9-ea2ae2bc0098/Relatório+de+Gestáo+2016.pdf?MOD=AJPERES\&CVID >. Acesso em: 29 junho 2020.

, EPE. Balanço Energético Nacional 2018: Ano Base 2017. 2018 
, MCT. Segunda comunicação nacional do Brasil à convenção-Quadro das nações unidas sobre Mudança do clima. 2010.

CARVALHO, Carlos Henrique Ribeiro de. Emissóes relativas de poluentes do transporte motorizado de passageiros nos grandes centros urbanos brasileiros. Texto para Discussão, Instituto de Pesquisa Econômica Aplicada (IPEA), 2011.

CRUVINEL, Rodrigo Rosa da Silva; PINTO, Paulo Victor Hermetério; GRANEMANN, Sérgio Ronaldo. Mensuração econômica da emissão de $\mathrm{CO}_{2}$ da frota dos transportadores autônomos de cargas brasileiros. Journal of Transport Literature, v. 6, n. 2, p. 234-252, 2012.

DORNBUSCH, Rudiger; FISCHER, Stanley; STARTZ, Richard. Macroeconomia.11 edição. Tradução de João Gama. 2013.

DÖRNER, Stefan Hubertus; BRAUN, Mirian Beatriz Schneider. As políticas comerciais do Brasil entre 1994 e 2014 e seus efeitos sobre a produtividade da indústria automobilística. Economia \& Regiáo, v. 3, n. 1, p. 141-159, 2015.

GOMES, Vallência Maíra; FARIA, Alexandre Magno de Melo; DALLEMOLE, Dilamar. Estimativa da Emissão de Gás Carbônico Derivado do Consumo de Combustíveis do Brasil e Mato Grosso entre 2000 e 2008: Identificando Contenção de Externalidades Negativas e Tendências de Ajustamento a uma Economia de Baixo Carbono. Revista de Estudos Sociais, v. 12, n. 24, p. 129-152, 2010.

IPCC. Climate change 2014: mitigation of climate change. Cambridge University Press, 2014.

Global warming of $1.5^{\circ} \mathrm{C}$ : An IPCC Special Report on the impacts of global warming of $1.5^{\circ} \mathrm{C}$ above pre-industrial levels and related global greenhouse gas emission pathways, in the context of strengthening the global response to the threat of climate change, sustainable development, and efforts to eradicate poverty. 2018.

. 2006 IPCC guidelines for national greenhouse gas inventories. Hayama, Japan:

Institute for Global Environmental Strategies, 2006.

JANSSENS-MAENHOUT, Greet et al. EDGAR v4.3.2 Global Atlas of the three major greenhouse gas emissions for the period 1970-2012. Earth System Science Data, v. 11, n. 3, p. 959-1002, 2019.

KOHLHEPP, Gerd. Análise da situação da produção de etanol e biodiesel no Brasil.

Estud. av., São Paulo, v. 24, n. 68, p. 223-253, 2010. 
MATTOS, Laura Bedeschi Rego de. A importância do setor de transportes na emissão de gases do efeito estufa: $\mathbf{O}$ caso do Município do Rio de Janeiro. 2001. Dissertação de Mestrado. Universidade Federal do Rio de Janeiro.

MENDONÇA, Mário Jorge Cardoso de; GUTIEREZ, Maria Bernadete Sarmiento. Efeito estufa e o setor energético brasileiro. Instituto de Pesquisa Econômica Aplicada (IPEA), 2000.

MORAES, Marcelo Lopes de; BACCHI, Mirian Rumenos Piedade. Etanol: do início às fases atuais de produção. Revista de Política Agrícola, v. 23, n. 4, p. 5-22, 2015.

OC - Observatório do Clima. Sistema de Estimativas de Gases de Efeito Estufa (SEEG V7.0), 2019.

OLIVIER, Jos GJ; SCHURE, K. M.; PETERS, J. A. H. W. Trends in global $\mathbf{C O}_{2}$ and total greenhouse gas emissions: 2017 Report. PBL Netherlands Environmental Assessment Agency, 2017.

TOLMASQUIM, Mauricio Tiomno; GUERREIRO, Amilcar; GORINI, Ricardo. Matriz energética brasileira: uma prospectiva. Novos estudos CEBRAP, n. 79, p. 47-69, 2007. 